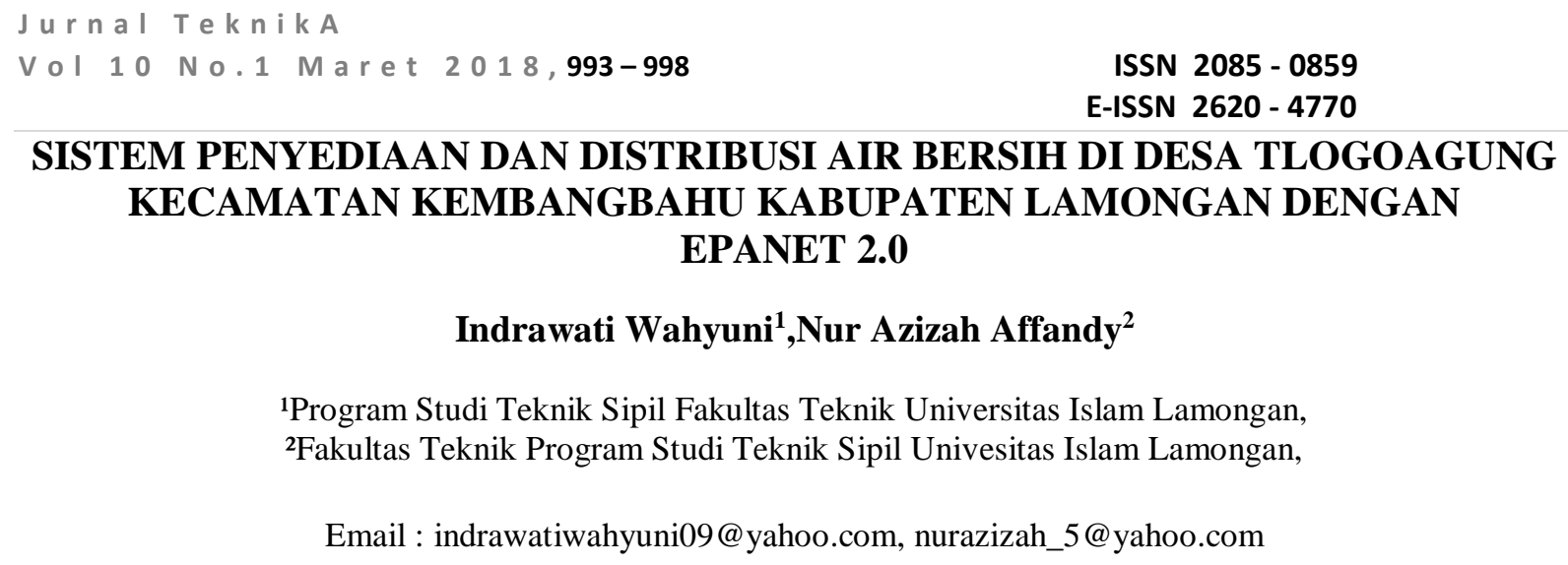

\section{SISTEM PENYEDIAAN DAN DISTRIBUSI AIR BERSIH DI DESA TLOGOAGUNG KECAMATAN KEMBANGBAHU KABUPATEN LAMONGAN DENGAN EPANET 2.0}

\author{
Indrawati Wahyuni ${ }^{1}$,Nur Azizah Affandy ${ }^{2}$ \\ 1Program Studi Teknik Sipil Fakultas Teknik Universitas Islam Lamongan, \\ ${ }^{2}$ Fakultas Teknik Program Studi Teknik Sipil Univesitas Islam Lamongan, \\ Email : indrawatiwahyuni09@yahoo.com,nurazizah_5@yahoo.com
}

\begin{abstract}
The availability of water is very important for human life, because water is a major human need. It is very important to plan a well-managed water supply system. Tlogoagung Village, Kembangbahu sub-district, Lamongan regency is one of the villages that have not yet a clean water distribution network, so it is necessary to plan clean water distribution network. The source of water used is the water source of the lake in the village. Clean water network system by making intake in lake then pumped to reservoir of distribution. Furthermore, it is distributed to the residential connection service area of the population with gravity system. A clean water network system is planned to meet the needs of clean water up to 2037. Clean water demand is calculated based on population projection by using linear analysis. From the calculation, the need of clean water in Tlogoagung village, Kembangbahu subdistrict of Lamongan regency in 2036 with the population of 4431 populations reach 7,431 ltr / sec, for transmission pipes using pipes with 4 inch or $0.1016 \mathrm{~m}$ diameters. For distribution pipes using 3 inch diameter pipes $0.0762 \mathrm{~m}$ or 2 inch diameter or 0.0508 , diameter $1 \frac{1}{1 / 2}$ or $0.0381 \mathrm{~m}$, diameter 1 inch or $0.0254 \mathrm{~m}$. To design a clean water distribution network using Epanet 2.0 software
\end{abstract}

Keyword: Population projection, a clean water distribution, pipe, Epanet

\section{PENDAHULUAN}

Perencanaan air bersih sering diabaikan, pada saat muncul masalah Seiring berkembangnya pengetahuan dan perncanaan mengenai pemukiman pada masa kini menuntut setiap orang dapat mengikuti perkembangannya agar menjadi sumber daya manusia yang lebih profesional.Salah satu upaya untuk meningkatkan kenyamanan tersebut diperlukan suatu sarana yang mendukung dalam segi pembangunan dalam segala keperluan . Seiring dengan itu perencanaan air bersih pada suatu daerah yang tidak dapat dilepaskan karena untuk memenuhi kebutuhan penghuni didalamnya.

Selain masalah tentang sumber air yang harus sesuai standar air bersih, masalah tekanan air pada pipa distribusi air bersih juga merupakan sesuatu yang sangat penting. Hal yang paling penting adalah debit air yang didistribusikan harus dapat memenuhi kebutuhan air pada desa Tlogoagung Kecamatan Kembangbahu Kabupaten Lamongan pada saat pemakaian normal ataupun pemakaian puncak. Berdasarkan latar belakang yang telah dijelaskan sebelumnya, maka permasalahan yang dapat dirumuskan adalah jumlah kebutuhan air bersih pada desa Tlogoagung Kecamatan Kembangbahu Kabupaten Lamongan tahun 2016 - 2036 serta air bersih di desa Tlogoagung Kec. Kembangbahu Kab. Lamongan dapat mengalir dengan baik. Tujuan dari penelitian ini untuk Mengetahui jumlah kebutuhan penyediaan air bersih pada Tlogoagung kecamatan Kembangbahu Kabupaten Lamongan tahun 2016 - 2036 serta sistem penyediaan air bersih menggunakan jaringan pipa untuk memenuhi kebutuhan air bersih desa Tlogoagung Kecamatan Kembangbahu Kabupaten Lamongan tahun 2016 - 2036. Studi kasus dilaksanakan pada desa Tlogoagung Kecamatan Kembangbahu Kab. Lamongan. Tinjauan yang mencakup penyediaan air bersih desa Tlogoagung Kecamatan Kembangbahu Kab. Lamongan tahun 2016 2036.

Untuk manfaat penelitian adalah mengembangkan ilmu pengetahuan di bidang teknik sipil sesuai teori yang didapat di bangku perkuliahan dan sebagai implementasi teori pada waktu perkuliahan khususnya di bidang perencanaan Air Bersih untuk kepentingan penelitian lebih lanjut bagi peneliti, manambah 
materi kuliah bagi Universitas, dari hasil penelitian dapat dijadikan dasar bagi Dinas PU PERA untuk mengambil kebijakan dalam memenuhi kebutuhan air bersih. pelayanan (konsumen).

\section{METODOLOGI PENELITIAN}

Metode penelitian yang digunakan adalah :

1. Studi literatur yang bertujuan untuk mendapatkan dukungan dan landasan teori dari buku-buku yang berhubungan dengan skripsi atau materi penelitian

2. Survey lokasi dan pengumpulan data Survey lokasi bertujuan untuk mengetahui kondisi lapangan yang sebenarnya dan permasalahan yang terjadi dan juga mengumpulkan data yang diperlukan.

3. Analisis data

4. Kesimpulan dan Saran

\section{HASIL DAN PEMBAHASAN}

Desa Kedungmegarih merupakan salah satu desa yang berada di ekcamatan Kembangbahu kabupaten Lamongan, terletak pada titik koordinat Lintang utara : $7^{0} 11^{\prime} 08.42$ " $\mathrm{S}$ dan Lintang selatan : $112^{0} 19^{\prime}$ 07.96" U. Secara umum keadaan topografi Desa Kedungmegarih adalah merupakan daerah pertanian dan termasuk dalam wilayah dataran rendah. Sebagian besar masyarakat desa Kedungmegarih berprofesi sebagai petani. Berdasarkan data yang didapat dari Balai Desa Kedungmeraih Jumlah penduduk adalah 3.148 jiwa.

\section{Analisis Regresi linier}

Tabel 1. Hasil Analisa Regresi Linier

\begin{tabular}{ccccccc}
\hline No & Tahun & $\begin{array}{c}\text { Nomor } \\
(\mathbf{x})\end{array}$ & $\begin{array}{c}\text { Jumlah } \\
\text { Penduduk } \\
(\mathbf{y})\end{array}$ & $\mathbf{x}^{\mathbf{2}}$ & $\mathbf{x y}$ & $\mathbf{y}^{\mathbf{2}}$ \\
\hline 1 & 2007 & 1 & 2,548 & 1 & 2,548 & $6,492,304$ \\
2 & 2008 & 2 & 2,564 & 4 & 5,128 & $6,574,096$ \\
3 & 2009 & 3 & 2,617 & 9 & 7,851 & $6,848,689$ \\
4 & 2010 & 4 & 2,698 & 16 & 10,792 & $7,279,204$ \\
5 & 2011 & 5 & 2,726 & 25 & 13,630 & $7,431,076$ \\
6 & 2012 & 6 & 2,785 & 36 & 16,710 & $7,756,225$ \\
7 & 2013 & 7 & 2,865 & 49 & 20,055 & $8,208,225$ \\
8 & 2014 & 8 & 2,919 & 64 & 23,352 & $8,520,561$ \\
9 & 2015 & 9 & 3,071 & 81 & 27,639 & $9,431,041$ \\
10 & 2016 & 10 & 3,148 & 100 & 31,480 & $9,909,904$
\end{tabular}

\begin{tabular}{cccccc} 
Jumlah & $\mathbf{5 5}$ & $\mathbf{2 7 , 9 4 1}$ & $\mathbf{3 8 5}$ & $\mathbf{1 5 9 , 1 8 5}$ & $\mathbf{7 8 , 4 5 1 , 3 2 5}$ \\
\hline Sumber : Hasil Analisa & & & &
\end{tabular}

Hasil perhitungan proyeksi penduduk. Berdasarkan analisa regresi linier hasilnya dapat dilihat pada tabel 1

\section{Proyeksi Jumlah Penduduk}

Tabel 2. Proyeksi Jumlah Penduduk

\begin{tabular}{cccc}
\hline No & Tahun & $\mathbf{x}$ & $\begin{array}{c}\text { Jumlah } \\
\text { Penduduk } \\
\text { (jiwa) }\end{array}$ \\
\hline 1 & 2017 & 11 & 3,162 \\
2 & 2018 & 12 & 3,229 \\
3 & 2019 & 13 & 3,295 \\
4 & 2020 & 14 & 3,362 \\
5 & 2021 & 15 & 3,429 \\
6 & 2022 & 16 & 3,496 \\
7 & 2023 & 17 & 3,563 \\
8 & 2024 & 18 & 3,629 \\
9 & 2025 & 19 & 3,696 \\
10 & 2026 & 20 & 3,763 \\
11 & 2027 & 21 & 3,830 \\
12 & 2028 & 22 & 3,896 \\
13 & 2029 & 23 & 3,963 \\
14 & 2030 & 24 & 4,030 \\
15 & 2031 & 25 & 4,097 \\
16 & 2032 & 26 & 4,164 \\
17 & 2033 & 27 & 4,230 \\
18 & 2034 & 28 & 4,297 \\
19 & 2035 & 29 & 4,364 \\
20 & 2036 & 30 & 4,431 \\
\hline Sumber : Hasil Analisa & &
\end{tabular}

Dari tabel diatas bahwa proyeksi penduduk pada tahun 2017 berjumlah 3.162 jiwa dan tahun 2036 meningkat menjadi 4.431 jiwa, pertumbuhan penduduk tiap tahun sebesar 1,2.

\section{Kebutuhan Air Domestik}

Kebutuhan air domestik adalah kebutuhan yang diperlukan manusia untuk kehidupan sehari-hari seperti minum, masak, MCK, bersihbersih dan lain-lain.

\section{Tabel 3. Kebutuhan Air Domestik}

\begin{tabular}{|c|c|c|c|c|}
\hline No & Tahun & $\begin{array}{c}\text { Jumlah } \\
\text { Pendu } \\
\text { duk } \\
\text { (jiwa) }\end{array}$ & $\begin{array}{c}\text { Kebut } \\
\text { uhan } \\
\text { air } \\
\text { bersih } \\
\text { (lt/hr) }\end{array}$ & $\begin{array}{c}\text { Kebutuhan } \\
\text { air bersih } \\
\text { (lt/det) }\end{array}$ \\
\hline 1 & 2017 & 3162 & 189720 & 2.196 \\
\hline 2 & 2018 & 3229 & 193740 & 2.242 \\
\hline 3 & 2019 & 3295 & 197700 & 2.288 \\
\hline 4 & 2020 & 3362 & 201720 & 2.335 \\
\hline 5 & 2021 & 3429 & 205740 & 2.381 \\
\hline 6 & 2022 & 3496 & 209760 & 2.428 \\
\hline
\end{tabular}




\begin{tabular}{ccccc}
\hline No & Tahun & $\begin{array}{c}\text { Jumlah } \\
\text { Pendu } \\
\text { duk } \\
\text { (jiwa) }\end{array}$ & $\begin{array}{c}\text { Kebut } \\
\text { uhan } \\
\text { air } \\
\text { bersih } \\
\text { (lt/hr) }\end{array}$ & $\begin{array}{c}\text { Kebutuhan } \\
\text { air bersih } \\
\text { (lt/det) }\end{array}$ \\
\hline 7 & 2023 & 3563 & 213780 & 2.474 \\
8 & 2024 & 3629 & 217740 & 2.520 \\
9 & 2025 & 3696 & 221760 & 2.567 \\
10 & 2026 & 3763 & 225780 & 2.613 \\
11 & 2027 & 3830 & 229800 & 2.660 \\
12 & 2028 & 3896 & 233760 & 2.706 \\
13 & 2029 & 3963 & 237780 & 2.752 \\
14 & 2030 & 4030 & 241800 & 2.799 \\
15 & 2031 & 4097 & 245820 & 2.845 \\
16 & 2032 & 4164 & 249840 & 2.892 \\
17 & 2033 & 4230 & 253800 & 2.938 \\
18 & 2034 & 4297 & 257820 & 2.984 \\
19 & 2035 & 4364 & 261840 & 3.031 \\
20 & 2036 & 4431 & 265860 & 3.077 \\
\hline Sum
\end{tabular}

Sumber : Hasil Analisa

Dari hasil analisa pada tabel 5.3 bahwa jumlah kebutuhan air bersih untuk domestik pada tahun 2036 adalah $264860 \mathrm{ltr} / \mathrm{hr} \sim 11077500$ ltr/jam 3,077 ltr/dtk

\section{Kebutuhan Air non Domestik}

Kebutuhan air non domestik adalah kebutuhan untuk fasilitas pelayanan umum, seperti kantor, sekolah, puskesmas, tempat ibadah. Kebutuhan air non domestik adalah 5\% dari kebutuhan air domestic

\section{Tabel 4. Kebutuhan Air non Domestik}

\begin{tabular}{|c|c|c|c|c|}
\hline \multirow{2}{*}{ No } & \multirow{2}{*}{ Tahun } & \multicolumn{3}{|c|}{ Kebutuhan Air Non Domestik } \\
\hline & & ltr/hari & Itr/dtk & $\mathbf{m}^{3} / \mathbf{d t k}$ \\
\hline 1 & 2017 & 9486 & 0.1098 & 0.000110 \\
\hline 2 & 2018 & 9687 & 0.1121 & 0.000112 \\
\hline 3 & 2019 & 9885 & 0.1144 & 0.000114 \\
\hline 4 & 2020 & 10086 & 0.1167 & 0.000117 \\
\hline 5 & 2021 & 10287 & 0.1191 & 0.000119 \\
\hline 6 & 2022 & 10488 & 0.1214 & 0.000121 \\
\hline 7 & 2023 & 10689 & 0.1237 & 0.000124 \\
\hline 8 & 2024 & 10887 & 0.1260 & 0.000126 \\
\hline 9 & 2025 & 11088 & 0.1283 & 0.000128 \\
\hline 10 & 2026 & 11289 & 0.1307 & 0.000131 \\
\hline 11 & 2027 & 11490 & 0.1330 & 0.000133 \\
\hline 12 & 2028 & 11688 & 0.1353 & 0.000135 \\
\hline 13 & 2029 & 11889 & 0.1376 & 0.000138 \\
\hline 14 & 2030 & 12090 & 0.1399 & 0.000140 \\
\hline 15 & 2031 & 12291 & 0.1423 & 0.000142 \\
\hline 16 & 2032 & 12492 & 0.1446 & 0.000145 \\
\hline 17 & 2033 & 12690 & 0.1469 & 0.000147 \\
\hline 18 & 2034 & 12891 & 0.1492 & 0.000149 \\
\hline 19 & 2035 & 13092 & 0.1515 & 0.000152 \\
\hline 20 & 2036 & 13293 & 0.1539 & 0.000154 \\
\hline
\end{tabular}

\section{Kehilangan Air}

Kehilangan air umumnya disebabkan karena adanya kebocoran pada pipa serta kesalahan pada pembacaan meter. Berdasarkan kriteria perencanaan IKK pedesaan pada tahun 1990 kebocoran atau kehilangan air yaitu 15\% dari kebutuhan rata-rata, dimana kebutuhan rata-rata adalah hasil penjumlahan dari kebutuhan air domestik dan kebutuhan air non domestik.

\section{Tabel 5. Kehilangan Air}

\begin{tabular}{|c|c|c|c|c|c|c|c|}
\hline \multirow{2}{*}{ No } & \multirow{2}{*}{ Tahun } & \multicolumn{2}{|c|}{$\begin{array}{c}\text { Kebutuhan Air } \\
\text { Domestik }\end{array}$} & \multicolumn{2}{|c|}{$\begin{array}{l}\text { Kebutuhan Air } \\
\text { Non Domestik }\end{array}$} & \multicolumn{2}{|c|}{$\begin{array}{c}\text { Kehilangan Air } \\
\text { Total }\end{array}$} \\
\hline & & Itr/hari & $\begin{array}{l}\text { Itr/ } \\
\text { dt }\end{array}$ & Itr/hr & $\begin{array}{l}\text { ltr/ } \\
\text { dt }\end{array}$ & ltr $/ \mathbf{h r}$ & $\begin{array}{l}\text { Itr/ } \\
\text { dt }\end{array}$ \\
\hline 1 & 2018 & 189720 & 2.20 & 9486 & 0.11 & 29881 & 0.35 \\
\hline 2 & 2019 & 193740 & 2.24 & 9687 & 0.11 & 30514 & 0.35 \\
\hline 3 & 2020 & 197700 & 2.29 & 9885 & 0.11 & 31138 & 0.36 \\
\hline 4 & 2021 & 201720 & 2.33 & 10086 & 0.12 & 31771 & 0.37 \\
\hline 5 & 2022 & 205740 & 2.38 & 10287 & 0.12 & 32404 & 0.38 \\
\hline 6 & 2023 & 209760 & 2.43 & 10488 & 0.12 & 33037 & 0.38 \\
\hline 7 & 2024 & 213780 & 2.47 & 10689 & 0.12 & 33670 & 0.39 \\
\hline 8 & 2025 & 217740 & 2.52 & 10887 & 0.13 & 34294 & 0.40 \\
\hline 9 & 2026 & 221760 & 2.57 & 11088 & 0.13 & 34927 & 0.40 \\
\hline 10 & 2027 & 225780 & 2.61 & 11289 & 0.13 & 35560 & 0.41 \\
\hline 11 & 2028 & 229800 & 2.66 & 11490 & 0.13 & 36194 & 0.42 \\
\hline 12 & 2029 & 233760 & 2.71 & 11688 & 0.14 & 36817 & 0.43 \\
\hline 13 & 2030 & 237780 & 2.75 & 11889 & 0.14 & 37450 & 0.43 \\
\hline 14 & 2031 & 241800 & 2.80 & 12090 & 0.14 & 38084 & 0.44 \\
\hline 15 & 2032 & 245820 & 2.85 & 12291 & 0.14 & 38717 & 0.45 \\
\hline 16 & 2033 & 249840 & 2.89 & 12492 & 0.14 & 39350 & 0.46 \\
\hline 17 & 2034 & 253800 & 2.94 & 12690 & 0.15 & 39974 & 0.46 \\
\hline 18 & 2035 & 257820 & 2.98 & 12891 & 0.15 & 40607 & 0.47 \\
\hline 19 & 2036 & 261840 & 3.03 & 13092 & 0.15 & 41240 & 0.48 \\
\hline 20 & 2037 & 265860 & 3.08 & 13293 & 0.15 & 41873 & 0.48 \\
\hline
\end{tabular}

Sumber : Hasil Analisa

Dari hasil analisa tabel 5.4. untuk kebutuhan air bersih non domestik pada tahun 2036 sebesar 13293 ltr/jam 0,15539 ltr/dtk

\section{Kebutuhan Air Total}

Kebutuhan air total adalah total kebutuhan air domestik, non domestik dan kehilangan air. Perhitungan kebutuhan air total dapat dilihat pada tabel 4.6 dari tahun 2017 sampai dengan 2036.

Tabel 6. Kebutuhan Air Total

\begin{tabular}{cccr}
\hline \multirow{2}{*}{ No } & \multirow{2}{*}{ Tahun } & \multicolumn{2}{c}{ Kebutuhan Air Total } \\
\cline { 3 - 4 } & & ltr/hari & ltr/dtk \\
\hline 1 & 2018 & 229087 & 2.651 \\
2 & 2019 & 233941 & 2.708 \\
3 & 2020 & 238723 & 2.763 \\
4 & 2021 & 243577 & 2.819 \\
5 & 2022 & 248431 & 2.875
\end{tabular}




\begin{tabular}{cccc}
6 & 2023 & 253285 & 2.932 \\
7 & 2024 & 258139 & 2.988 \\
8 & 2025 & 262921 & 3.043 \\
9 & 2026 & 267775 & 3.099 \\
10 & 2027 & 272629 & 3.155 \\
11 & 2028 & 277484 & 3.212 \\
12 & 2029 & 282265 & 3.267 \\
13 & 2030 & 287119 & 3.323 \\
14 & 2031 & 291974 & 3.379 \\
15 & 2032 & 296828 & 3.436 \\
16 & 2033 & 301682 & 3.492 \\
17 & 2034 & 306464 & 3.547 \\
18 & 2035 & 311318 & 3.603 \\
19 & 2036 & 316172 & 3.659 \\
20 & 2037 & 321026 & 3.716 \\
\hline
\end{tabular}

Sumber : Hasil Analisa

Kebutuhan air total desa Tlogoagung kecamatan Kembangbahu kabupaten Lamongan dari hasil analisa pada tabel 6 pada tahun 2036 adalah $321026 \mathrm{ltr} / \mathrm{hr} \sim 3,716 \mathrm{ltr} / \mathrm{dtk}$

\section{Kebutuhan Air maksimum dan jam puncak}

Kebutuhan air harian maksimum dihitung berdasarkan kebutuhan air rata-rata dikali factor pengali yaitu berkisar 1.05-1.15

Tabel 7. Kebutuhan Air maksimum dan jam puncak

\begin{tabular}{cccccc}
\hline & & \multicolumn{2}{c}{ Kebutuhan air } & \multicolumn{2}{c}{ Kebutuhan air } \\
No & Tahun & \multicolumn{2}{c}{ harian maksimum } & \multicolumn{2}{c}{ jam puncak } \\
& & ltr/hari & ltr/dtk & ltr/hari & ltr/dtk \\
\hline 1 & 2018 & 263449.94 & 3.049 & 458173.80 & 5.303 \\
2 & 2019 & 269032.21 & 3.114 & 467882.10 & 5.415 \\
3 & 2020 & 274531.16 & 3.177 & 477445.50 & 5.526 \\
4 & 2021 & 280113.44 & 3.242 & 487153.80 & 5.638 \\
5 & 2022 & 285695.71 & 3.307 & 496862.10 & 5.751 \\
6 & 2023 & 291277.98 & 3.371 & 506570.40 & 5.863 \\
7 & 2024 & 296860.25 & 3.436 & 516278.70 & 5.975 \\
8 & 2025 & 302359.21 & 3.500 & 525842.10 & 6.086 \\
9 & 2026 & 307941.48 & 3.564 & 535550.40 & 6.199 \\
10 & 2027 & 313523.75 & 3.629 & 545258.70 & 6.311 \\
11 & 2028 & 319106.03 & 3.693 & 554967.00 & 6.423 \\
12 & 2029 & 324604.98 & 3.757 & 564530.40 & 6.534 \\
13 & 2030 & 330187.25 & 3.822 & 574238.70 & 6.646 \\
14 & 2031 & 335769.53 & 3.886 & 583947.00 & 6.759 \\
15 & 2032 & 341351.80 & 3.951 & 593655.30 & 6.871 \\
16 & 2033 & 346934.07 & 4.015 & 603363.60 & 6.983 \\
17 & 2034 & 352433.03 & 4.079 & 612927.00 & 7.094 \\
18 & 2035 & 358015.30 & 4.144 & 622635.30 & 7.206 \\
19 & 2036 & 363597.57 & 4.208 & 632343.60 & 7.319 \\
20 & 2037 & 369179.84 & 4.273 & 642051.90 & 7.431 \\
\hline Sumber : Hasil Analisa & & & \\
\hline
\end{tabular}

Dari hasil perhitungan dan analisa pada tabel 4.6 bahwa pada tahun 2036 desa Tlogoagung kecamatan Kembangbahu kabupaten Lamongan kebutuhan air maksimum sebesar 4,273 ltr/dtk dan kebutuhan air jam puncak sebesar 7,431 ltr/dtk.

\section{Perencanaan Sistem Penyediaan Air Bersih}

\section{Desain Bangunan Intake}

Intake merupakan bangunan yang berfungsi sebagai penyadap dari air telaga, menyaring dari benda-benda kasar dan menjaga kuantitas dari air baku tersebut.

Desain Hidrolis Reservoir. Ukuran kapasitas berguna reservoar : $\mathrm{v}=5,5 \mathrm{~m} \quad ; \mathrm{T}$ air $=4,4 \mathrm{~m}$ Tinggi $=$ kedalaman dari kapasitas air berguna. Kontrol :

Dimensi kapasitas berguna > Kapasitas reservoar yang dibutuhkan :

$136,125 \mathrm{~m}^{3}>128.39 \mathrm{~m}^{3}$

Jadi dimensi reservoar menjadi $(5.5 \times 5.5 \times 5.5) \mathrm{m}$

\section{Desain Jaringan Perpipaan}

Dalam mendesain jaringan perpipaan pipa yang digunakan adalah PVC.

\section{Pompa dan Pipa transmisi :}

Perhitungan untuk pipa transmisi dan pompa sentrifugal dihitung secara manual dengan menggunakan rumus Hazen William.

- Pipa Hisap

Diketahui :

$$
\begin{array}{ll}
\text { Panjang (L) } & : 8 \mathrm{~m} \\
\text { Q air } & : 0,00743 \mathrm{~m}^{3} / \mathrm{dtk} \\
\mathrm{C}_{\mathrm{hw}} & : 145 \\
\Delta \mathrm{H} & : 1 \mathrm{~m} \\
\mathrm{D} & : 5 \text { inch }: 0,106 \mathrm{~m} \\
& h f=\frac{\left(10.684 .0,00743^{1,85}\right)}{145^{1,85} 0,106^{4,87}} 8 \\
& \mathrm{hf}=0,0635 \mathrm{~m}
\end{array}
$$

Kontrol : hf $<\Delta \mathrm{h}$

$$
\text { : } 0,0635<1
$$

Pipa Transmisi :

Diketahui :

$$
\begin{array}{lc}
\text { Panjang (L) } & : 15 \mathrm{~m} \\
\mathrm{Q} \text { air } & : 0,00743 \mathrm{~m}^{3} / \mathrm{dtk} \\
\mathrm{C}_{\mathrm{hw}} & : 145 \\
\Delta \mathrm{H} & : 1 \mathrm{~m} \\
\mathrm{D} & : 4 \text { inch }: 0,1016 \mathrm{~m} \\
& \quad h f=\frac{\left(10.684 .0,00743^{1,85}\right)}{150^{1,85} 0,1016^{4,87}} 20
\end{array}
$$


$\begin{aligned} \text { hf } & =0,119 \\ \text { Kontrol }: & \text { hf }<\Delta \text { h }\end{aligned}$

: $0,119<1$ OK

\section{Pipa Distribusi}

Menggunakan analisa program Epanet 2.0

\begin{tabular}{|c|c|c|c|c|c|}
\hline \multicolumn{6}{|c|}{ 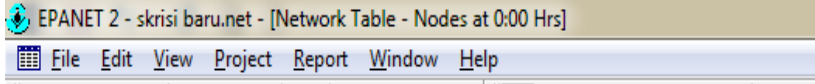 } \\
\hline \multirow[t]{2}{*}{ 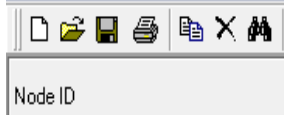 } & 约? ? 橉 四 & \multicolumn{3}{|c|}{$\| \Delta ロ+\oplus \Theta " \square$} & \multirow{2}{*}{$\frac{\mid c t}{0}$} \\
\hline & \begin{tabular}{|c|} 
Demand \\
LPS
\end{tabular} & \begin{tabular}{c|c} 
Head \\
$\mathrm{m}$
\end{tabular} & $\begin{array}{c}\text { Pressure } \\
\mathrm{m}\end{array}$ & Quality & \\
\hline Junc 2 & 2.20 & 48.79 & 15.79 & & 0.00 \\
\hline Junc 3 & 1.30 & 48.38 & 12.38 & & 0.00 \\
\hline Junc 4 & 1.02 & 47.69 & 15.69 & & 0.00 \\
\hline Junc 5 & 0.62 & 46.70 & 16.70 & & 0.00 \\
\hline Junc 6 & 0.19 & 48.87 & 10.87 & & 0.00 \\
\hline \begin{tabular}{|l|} 
Junc 7 \\
\end{tabular} & 0.16 & 48.68 & 10.68 & & 0.00 \\
\hline Junc 8 & 1.10 & 47.41 & 13.41 & & 0.00 \\
\hline Junc 9 & 0.19 & 45.81 & 17.81 & & 0.00 \\
\hline Junc 10 & 0.65 & 45.23 & 14.23 & & 0.00 \\
\hline Tank 1 & .7 .43 & 49.00 & 8.00 & & 0.00 \\
\hline
\end{tabular}

Gambar 2.Hasil Analisa Epanet 2.0

\begin{tabular}{|c|c|c|c|c|c|c|c|}
\hline \multicolumn{8}{|c|}{ EPANET 2 - skrisi baru.net - [Network Table - Links at 0:00 Hrs] } \\
\hline \multicolumn{8}{|c|}{ 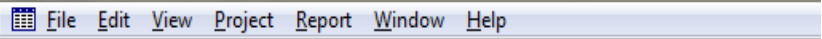 } \\
\hline 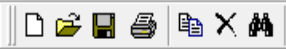 & 急 & \multicolumn{2}{|c|}{ ? 嘈四 } & \multicolumn{3}{|c|}{ 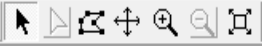 } & $\mathrm{Ot}$ \\
\hline Link ID & & $\begin{array}{l}\text { Flow } \\
\text { LPS }\end{array}$ & $\begin{array}{r}\text { Velo } \\
\mathrm{m} /\end{array}$ & & \begin{tabular}{c|} 
Unit Headloss \\
$\mathrm{m} / \mathrm{km}$
\end{tabular} & Friction $\mathrm{Fa}$ & Factor \\
\hline Pipe 2 & & 2.10 & & 0.48 & 3.30 & & 0.021 \\
\hline Pipe 3 & & 1.94 & & 0.44 & 2.85 & & 0.022 \\
\hline Pipe 4 & & 0.84 & & 0.43 & 4.36 & & 0.023 \\
\hline Pipe 5 & & 0.65 & & 0.33 & 2.71 & & 0.024 \\
\hline Pipe 7 & & 2.94 & & 0.37 & 1.51 & & 0.021 \\
\hline Pipe 8 & & 1.64 & & 0.37 & 2.09 & & 0.022 \\
\hline Pipe 1 & & 2.29 & & 0.29 & 0.96 & & 0.022 \\
\hline Pipe 6 & & 5.14 & & 0.29 & 0.59 & & 0.021 \\
\hline Pipe 9 & & 0.62 & & 0.32 & 2.48 & & 0.024 \\
\hline
\end{tabular}

Gambar 3. Hasil Analisa Epanet 2.0

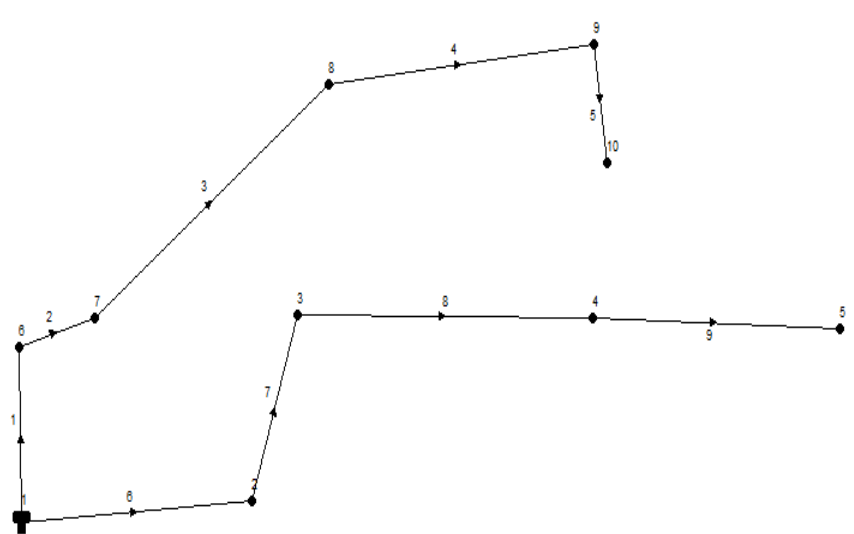

Gambar 4. Gambar Peta Jaringan Hasil Analisa

\section{KESIMPULAN}

Dari hasil penelitian di atas dapat diambil kesimpulan bahwa kebutuhan dan ketersediaan air bersih dari hasil analisa perhitungan kebutuhan air meliputi kebutuhan air domestik dan non domestik. Untuk kebutuhan air domestik pada tahun 2017 sebesar 2,196 ltr/dtk dan pada tahun 2036 sebesar 2,938 ;tr/dtk. Untuk kebutuhan air non domestik pada tahun 2018 sebesar 0.1098 ltr/dtk dan pada tahun 2037 adalah $0.1469 \mathrm{ltr} / \mathrm{dtk}$.

Untuk kehilangan air pada tahun 2017 sebanyak 0.346 ltr/dtk dan pada tahun 2037 sebanyak 0,485 ltr/dtk. Sehingga kebutuhan air total pada tahun 2018 adalah 2,561 ltr/dtk dan kebutuhan air total pada tahun 2036 sebesar 7,595 ltr/dtk.

Untuk kebutuhan air harian maksimum pada tahun 2017 adalah sebanyak 3,049 ltr/dtk dan pada tahun 2036 adalah sebannyak 4,273 ltr/dtk . dan untuk kebutuhan air jam puncak pada tahun 2017 adalah sebanyak 5,303 ltr/dtk dan pada tahun 2036 adalah sebannyak 7,43 ltr/dtk

Sumber air bersih yang dipergunakan adalah telaga yang ada di desa Tlogoagung kecamatan Kembangbahu kabupaten Lamongan dengan debit 5,2 ltr/dtk. Kebutuhan air total untuk 20 tahun yang akan datang sebesar 3,716 ltr/dtk sehingga sumber air bersih ini masih cukup untuk 20 tahun yaitu pada ahun 2036 .

Sistem jaringan Air Bersih : Intake : bangunan ini terbuat dari buis beton dengan diameter $100 \mathrm{~cm}$ yang disusun ke atas. Rerservoir : berkapasitas $128,39 \mathrm{~m}^{3}$ dengan dimensi panjang : 5,5 $\mathrm{m}$ tinggi 5,5 $\mathrm{m}$ dan lebar 5,5 m.Desain jaringan air bersih untuk pipa transmsi menggunakan pipa dengan dimater 4 inch atau 0,1016 $\mathrm{m}$. Untuk pipa distribusi menggunakan pipa diameter 3 inch $0.0762 \mathrm{~m}$ atau, diameter 2 inch atau 0,0508 , diameter $1 \frac{1}{2}$ inchi atau 0,0381 m, diameter 1 inch atau 0,0254 $\mathrm{m}$.

\section{REFERENSI}

Anonimous, 1990, Pedoman Air Minum Perdesaan, Direktorat Jendral Cipta Karya Departemen PU 
Triatmadja, Radianta, 2007, Sistem Penyediaan Air Minum Perpipaan, Yogyakarta

Linsley,R.K dan Fransini, J.B, 1991, Teknik Sumber Daya Air jilid 1 \& 2, Erlangga, Jakarta
Triadmodjo, B., 1996, Hidrolika II, Beta Offset, Yogyakarta

Kodoatie, Robert J, 2002, Hidrolika Terapan, Andi Puplisher, Yogyakarta Anonimous, 2010, Buku Manual Program Epanet.pdf 